\title{
INTERFACES ENTRE AVALIAÇÃO INSTITUCIONAL E GESTÃO DE INSTITUIÇÕES DE ENSINO SUPERIOR: UM ESTUDO A PARTIR DO SINAES
}

http://dx.doi.org/10.5902/2318133826509

\author{
Felipe Barbosa Ferronato \\ Universidade do Vale do Sapucaí, Brasil.
}

\begin{abstract}
Resumo
Este artigo se relaciona com a dissertação intitulada Interfaces entre avaliação institucional e gestão de instituições de ensino superior: um estudo a partir do Sinaes. A lei n. 10.861 de 2004, que instituiu o Sistema Nacional de Avaliação da Educação Superior - Sinaes - e suas adaptações posteriores apresenta um modelo implícito de administração destinado às instituições de ensino superior ao indicar ações e estratégias para a gestão, compondo indicadores para a avaliação final. Com a institucionalização do Sinaes a avaliação passou a ocupar centralidade na política de regulação da oferta, qualidade e expansão da educação superior a partir de indicadores. A questão desta pesquisa se concentrou na centralidade ocupada pela avaliação como fornecedora de indicadores para fins de regulação. O objetivo central foi identificar e analisar as interfaces das dimensões do Sinaes com as dimensões da Administração, tomando como amparo teórico a teoria de gestão de Drucker (2012). A pesquisa é de natureza qualitativa e abordagem dialéticocrítica, sem desconsiderar os aspectos quantitativos no processo de análise e discussão. Foi utilizada a pesquisa documental (Laville; Dione, 2009), considerando como material de análise instrumentos legais, impressos e eletrônicos, informações e dados consultados no MEC/Inep. Demonstrou-se que há uma nítida e forte relação do modelo avaliativo proposto pelo MEC, por meio do Sinaes, com a dimensão administrativa das instituições de ensino superior. As dimensões do processo de avaliação vão encontro das características do modelo de gestão (Drucker, 2012), principalmente, pelo foco das ações e estratégias no planejamento e nos resultados, sendo a avaliação inerente à administração, mas evidenciando a preocupação com o caráter humano que perpassa essas entidades, pois a realização de qualquer administração depende de resultados e são os resultados que transformam a gestão.

Palavras-chave: administração, avaliação, gestão, Sinaes, regulação.
\end{abstract}

\section{INTERFACES BETWEEN INSTITUTIONAL EVALUATION AND MANAGEMENT OF HIGHER EDUCATION INSTITUTIONS: A STUDY FROM SINAES}

\section{Abstract}

This article is related to the dissertation entitled Interfaces between the institutional assessment and management of institutions of higher learning: a study of the Sinaes. Law 10,861 of 2004, which established the National System for Assessment of Higher Education - Sinaes - and its subsequent adaptations present an implicit model of administration aimed at institutions of higher learning, by indicating actions and strategies for their management, composing indicators for final assessment. With the institutionalization of the Sinaes, the assessment came to occupy a central position in the policy for regulating the supply, quality and expansion of higher education based on indicators. The question of this study is focused on the centrality occupied by the assessment as a supplier of indicators for purposes of regulation. The central objective is to identify and analyze the

\begin{tabular}{|l|l|l|l|l|l|} 
Regae: Rev. Gest. Aval. Educ. & Santa Maria & v. 6 & n. 11 & Jan./abr. 2017 & p. $21-43$
\end{tabular} 
interfaces of the dimensions of the Sinaes with the dimensions of the public administration, based on the management theory of Drucker (2012). The study is qualitative in nature, with a dialecticcritical approach, without neglecting the quantitative aspects in the process of analysis and discussion. Documental research was used (Laville \& Dione, 2009), considering as material for analysis legal instruments, in printed and electronic form, as well as information and data obtained from consulting the Ministry of Education/National Institute of Educational Studies - MEC/Inep. The results demonstrate a clear relationship between the assessment model proposed by the MEC, through the Sinaes, and the administrative dimension of the institutions of higher learning. The dimensions of the assessment process are in line with the characteristics of the management model considered (Drucker, 2012), mainly the focus on actions and strategies for planning and their results. This assessment is inherent in public administration, but there is worry over the human character of these entities, because the performance of any management act depends on results, and it is the results that transform management.

Key-words: administration, assessment, management, Sinaes, regulation. 


\section{Introdução}

ste artigo origina-se de uma dissertação vinculada à Linha de Pesquisa Práticas Educativas e Formação do Profissional Docente do Mestrado em Educação da Universidade do Vale do Sapucaí - Univás. Têm como objeto de estudo as dez dimensões do Sistema Nacional de Avaliação do Ensino Superior - Sinaes as quais são comparadas com as dimensões da Administração propostas por Peter Drucker (2012).

Assim, em 2004 foi instituído, pelo Ministério da Educação - MEC - o Sistema Nacional de Avaliação da Educação Superior - Sinaes -, lei n. 10.861, de 14 de abril de 2004 (Brasil, 2004), que institucionalizou a avaliação das instituições de ensino superior. Nesse cenário intensificou-se a discussão a respeito da avaliação da qualidade da educação superior brasileira, assim como as críticas aos mecanismos de avaliação. Desde então a avaliação passou a ocupar o centro das discussões no ambiente acadêmico das IES por diversos vieses: ora na implantação de ações para atender às exigências do MEC, ora discutindo propostas para amenizar e enfrentar as resistências e as críticas por parte dos docentes, discentes e técnicos, ora discutindo mecanismos para tornar a avaliação viável, mais eficiente e mais levada a sério, inclusive pelos gestores.

O Sinaes se organiza em dez dimensões que congregam os indicadores de qualidade propostos pelo MEC no contexto da regulação da qualidade e da oferta educação superior, a saber:

I - a missão e o plano de desenvolvimento institucional;

II - a política para o ensino, a pesquisa, a pós-graduação, a extensão e as respectivas formas de operacionalização, incluídos os procedimentos para estímulo à produção acadêmica, as bolsas de pesquisa, de monitoria e demais modalidades;

II - a responsabilidade social da instituição, considerada especialmente no que se refere à sua contribuição em relação à inclusão social, ao desenvolvimento econômico e social, à defesa do meio ambiente, da memória cultural, da produção artística e do patrimônio cultural;

IV - a comunicação com a sociedade;

V - as políticas de pessoal, as carreiras do corpo docente e do corpo técnicoadministrativo, seu aperfeiçoamento, desenvolvimento profissional e suas condições de trabalho;

VI - organização e gestão da instituição, especialmente o funcionamento e representatividade dos colegiados, sua independência e autonomia na relação com a mantenedora, e a participação dos segmentos da comunidade universitária nos processos decisórios;

VII - infraestrutura física, especialmente a de ensino e de pesquisa, biblioteca, recursos de informação e comunicação;

VIII - planejamento e avaliação, especialmente os processos, resultados e eficácia da auto avaliação institucional;

IX - políticas de atendimento aos estudantes;

$X$ - sustentabilidade financeira, tendo em vista o significado social da continuidade dos compromissos na oferta da educação superior (Brasil, 2004). 
O Sinaes é tomado, neste trabalho, como um marco na história da gestão da qualidade da educação superior, sendo expressão das necessidades políticas e econômicas do desenvolvimento nacional e de demandas globais, como destacado por Ristoff (2011), mas também como mecanismo de regulação da educação superior.

\section{Abordagem e percurso metodológico}

A metodologia da análise documental se apresentou como a mais adequada diante das questões e dos objetivos que orientam este trabalho, amparando-se nos conceitos de documentos propostos por Laville e Dione (2009). Segundo os autores o termo documental designa toda fonte de informações já existente que pode fornecer ao pesquisador os dados necessários na tarefa, muitas vezes árdua, de coleta de informações.

Uma vez identificadas essas interfaces utilizou-se a técnica interpretativo-descritiva dos referenciais teóricos selecionados para este estudo, quais sejam: os documentos do Sinaes/MEC, lei n. 10.861, de abril de 2004, e suas respectivas regulamentações, tais como a portaria n. 40/2007, republicada em 2010, e a portaria n. 92/2014, a nota técnica n. 062/2014, Dias Sobrinho (2003, 2008), Ristoff (2011), Dourado (2003). No caso dos fundamentos teóricos da Administração o amparo teórico se baseou, fundamentalmente, em Drucker (2012), o qual defende que toda instituição tem uma missão diante da sociedade, mesmo aquelas que não têm fins lucrativos.

\section{O Sinaes e a avaliação}

A avaliação constitui, atualmente, uma política de Estado, graças ao Sinaes. Seus resultados são utilizados como base para o diagnóstico, gestão e aprofundamento de questões da educação superior, bem como para a implantação de políticas educacionais em um cenário de reconfiguração do ensino superior, orientado por ideais neoliberais globais.

Após dez anos de Sinaes é possível dizer que a avaliação ocupa, no Brasil, seguindo tendências internacionais, a centralidade do processo de gestão educacional das IES, uma vez que o MEC se baseia nos resultados da avaliação para a autorização e recredenciamento de cursos, bem como credenciamento de novas instituições de ensino superior. O novo ciclo avaliativo voltado à instituição vislumbra os mecanismos de ensino de uma IES e considera a missão e visão, as relações que se estabelecem no processo educacional, a estrutura e a dinâmica, além da participação da comunidade externa. Portanto, avaliação institucional pode ser considerada um elemento estruturante e estruturador da administração acadêmica.

O Sinaes (2004) estabeleceu que a qualidade da educação superior seja verificada, dentre outros procedimentos, via auto-avaliação e avaliação externa, estabelecendo como escopo dez dimensões que devem ser realizadas em duas etapas: a auto-avaliação, também caracterizada como avaliação interna, que é coordenada por uma comissão própria de avaliação, e a avaliação externa, que é realizada por uma comissão de professores especialistas designados pelo Ministério da Educação.

Os propósitos do Sinaes devem ser compreendidos no cenário de forte expansão e diversificação do ensino superior brasileiro, como expressão das necessidades políticas e econômicas do desenvolvimento nacional e de demandas também globais (Ristoff, 2011). 
Nesse contexto, trata-se de entendê-lo como um sistema de avaliação dos serviços prestados pelas IES com a finalidade de gerenciar a qualidade desses serviços educacionais, inserindo-o no contexto da reforma do aparelho de Estado, a qual tem como meta principal uma mudança no modelo de administração pública para um modelo gerencial (Brasil, 1995).

A gestão do Sinaes para a coleta de informações, conforme previsto na lei n. 10.861, prevê o Censo da Educação Superior - integrado ao Sinaes, incluindo informações sobre atividades de extensão -, o cadastro de cursos e instituições - integrado ao Sinaes e a Comissão Própria de Avaliação - CPA.

\section{Administração}

Para Drucker (2012) empreendedor é a capacidade que o gestor deve ter de redirecionar recursos de áreas de resultados baixos ou decrescentes para áreas de resultados altos ou crescentes. Ele precisa descartar o passado e tornar obsoleto o que já existe e o que já é conhecido para, assim, planejar o amanhã, gerenciar os resultados e verificar as avaliações.

Nesta linha de pensamento Drucker (2012) chama atenção sobre a política de atendimento, que esta atividade exige por estar no centro dos custos e dos resultados. $O$ custo por cliente, em qualquer área importante da atividade, é fixo. Portanto, será o rendimento por cliente - o volume de serviço que um cliente usa e a combinação desses serviços - que determinará os custos e a rentabilidade. Os empresários europeus sabem disso há muito tempo. Entendem que, assim que se instalar uma unidade de espaço de qualquer que seja o negócio, o custo está fixado e a administração consistirá em maximizar o seu rendimento durante um determinado período de tempo. Para atingir a tais proposições Drucker (2012) propõe algumas ferramentas as quais denomina de dimensões da administração:

- primeira dimensão: propósito e missão;

- segunda dimensão: as políticas para o desenvolvimento de novas tecnologias;

- terceira dimensão: responsabilidade social;

- quarta dimensão: observação da sociedade;

- quinta dimensão: políticas de pessoal, planos de carreira;

- sexta dimensão: planejamento institucional;

- sétima dimensão: infraestrutura física e recursos para desenvolver tarefas;

- oitava dimensão: planejamento e avaliação de resultados;

- nona dimensão: políticas de atendimento aos clientes, fornecedores e colaboradores;

- décima dimensão: sustentabilidade financeira e econômica. 


\section{Análise e discussão}

Eixo 1- Categoria em convergência: planejamento

Quadro 1 -

Interfaces entre as dimensões do Sinaes e da Administração.

\begin{tabular}{|l|l|l|}
\hline \multicolumn{3}{|c|}{ Eixo 1: Planejamento } \\
\hline \multicolumn{1}{|c|}{ Sinaes } & \multicolumn{1}{|c|}{ Administração } & \multicolumn{1}{c|}{ Convergência } \\
\hline $\begin{array}{l}\text { Planejamento e avaliação } \\
\text { institucional }\end{array}$ & $\begin{array}{l}\text { Planejamento e avaliação } \\
\text { dos resultados }\end{array}$ & Planejamento institucional \\
\hline $\begin{array}{l}\text { Planejamento } \\
\text { avaliação institucional }\end{array}$ & $\begin{array}{l}\text { Planejamento } \\
\text { avaliação de resultados }\end{array}$ & Planejamento \\
\hline
\end{tabular}

Para o Sinaes resultados e eficácia são como instrumentos integrados, elementos de um mesmo processo contínuo, partícipes da gestão da educação superior (Brasil, 2004). Esses fundamentos vão ao encontro da dimensão planejamento e da avaliação de resultados da Administração, teorizados por Drucker (2012), sobre a importância do planejamento para as organizações. Portanto, a dimensão planejamento está na confluência da avaliação como processo centrado no presente e no futuro institucional, a partir do balanço de fragilidades, de potencialidades e da vocação institucionais, valendo tanto para a avaliação, quanto para a gestão.

Para Drucker (2012, p. 36), "o planejamento propicia saber onde investir ou onde parar de investir", pois, caso contrário até mesmo empresas eficientes não sobreviverão, nem serão capaz de progredir se a eficiência for direcionada para coisas erradas ou equivocadas, ou seja, se não for eficaz. Como destaca o autor nem a maximização da eficiência possibilitaria a sobrevivência do fabricante se não houver um olhar para o mercado e "só então planejar a partir de uma avaliação de resultados" (p. 36). Portanto, no eixo planejamento e avaliação institucional é possível observar a mesma lógica teórica que põe esses procedimentos - planejamento e avaliação - como eixo número um.

Diante das dimensões da gestão, no que se refere ao planejamento e a sua importância institucional, se forem postos os indicadores de qualidade do Sinaes, conforme a portaria n. 92/2014, a saber: projeto/processo de autoavaliação institucional; autoavaliação institucional, que deve envolver participação da comunidade acadêmica; autoavaliação institucional e avaliações externas, que abrange análise e divulgação dos resultados; elaboração do relatório de autoavaliação, realizado pela CPA, pelo qual é possível observar as seguintes categorias comuns: eficácia, gerenciamento, foco nos resultados, trazendo a ideia de que planejamento leva à eficácia e a resultados. Portanto, a discussão de planejamento traz em si esses fatores.

Assim, diante dos fundamentos de Drucker (2012) cabe destacar que o planejamento deve ser contínuo e sistemático e também ser uma forma de monitoramento e de controle, pois dá aos gestores o maior conhecimento possível acerca do futuro. $\mathrm{O}$ processo de planejamento de qualquer organização envolve: a missão da organização; a visão; os valores; os objetivos e estratégias; o desdobramento das estratégias e monitoramento/ controle. É consenso nas teorias da Administração que o processo de gestão de qualquer organização envolve: planejamento, execução e acompanhamento. 
Portanto, é possível visualizar nesse fundamento teórico a ideia de avaliação como algo inerente toda e qualquer Administração, como defende Drucker (2012), sendo validado nas prerrogativas do Sinaes.

$\mathrm{Na}$ área educacional o planejamento traz o mesmo sentido, como é exemplo Menegolla e Santana (2003), que demonstram o implícito sentido pedagógico do ato de planejar e do planejamento. Também é exemplo Padilha (2003), que destaca o sentido dialógico necessário ao planejamento no ambiente educacional.

Portanto, na educação planejar é pensar e refletir sobre a ação já realizada, ideia de avaliação, para projetar novas ações, que é o planejamento. Como define Padilha (2003), planejamento "é um processo contínuo e sistematizado de projetar e decidir ações em relação ao futuro, em função de objetivos políticos, sociais e administrativas claramente definidas" (p. 31), ou seja, planejamento é um procedimento pensado detalhadamente sobre a necessidade do que se pretende alcançar com eficiência e eficácia, tendo em vista a maximização de resultados.

Com isso, observamos a centralidade do processo de planejamento junto com a avaliação como dois processos interdependentes enquanto indicadores de qualidade de educação e de administração. Com base nos autores aqui referenciados o planejamento e avaliação são os principais mecanismos para uma gestão de qualidade, independentemente da natureza da instituição, pois fornecem ferramentas que contribuem para administrar resultados eficazes, enxergar antecipadamente os problemas e ajudar a direcionar as tomadas de decisões.

Eixo 2 - Categoria em convergência: Missão, objetivos, responsabilidade social

Quadro 2 -

Interfaces entre as dimensões do Sinaes e da Administração.

\begin{tabular}{|l|l|l|}
\hline \multicolumn{2}{|c|}{ Eixo 2: Missão - Objetivos - Responsabilidade Social } \\
\hline \multicolumn{1}{|c|}{ Sinaes } & \multicolumn{1}{c|}{ Administração } & \multicolumn{1}{c|}{ Convergência } \\
\hline $\begin{array}{l}\text { Desenvolvimento } \\
\text { institucional }\end{array}$ & $\begin{array}{l}\text { Desenvolvimento } \\
\text { Institucional }\end{array}$ & Planejamento institucional \\
\hline Missão & Missão & Missão \\
\hline Objetivos & Objetivos & Objetivos \\
\hline Responsabilidade social & Responsabilidade social & Responsabilidade social \\
\hline Metas & Planejamento institucional & \\
\hline
\end{tabular}

Como observa-se no quadro 2, que se refere ao desenvolvimento institucional, três categorias perpassam diretamente as dimensões do Sinaes e as dimensões da Administração consideradas neste trabalho como convergência: missão, objetivos, responsabilidade social.

No caso do Sinaes o eixo Desenvolvimento institucional se desdobra nos seguintes indicadores de qualidade que são avaliados pelo MEC: missão institucional, metas e objetivos do PDI; coerência entre o PDI e as atividades de ensino de graduação e de pósgraduação; coerência entre o PDI e as práticas de extensão; coerência entre o PDI e as 
atividades de pesquisa/iniciação científica, tecnológica, artística e cultural; coerência entre o PDI e as ações institucionais [...]; coerência entre o PDI e as ações institucionais voltadas para o desenvolvimento econômico e social; coerência entre o PDI e ações de responsabilidade social [...]; internacionalização: coerência entre o PDI e as ações institucionais.

Sobre propósito ou missão Drucker (2012) afirma que uma instituição existe para realizar um propósito e uma missão, executar determinada função para a sociedade. $\mathrm{Na}$ organização de negócios isso poderá se traduzir em desempenho econômico, sendo necessário observar que as organizações empresariais e não empresariais são bastante diferentes no que se refere à dimensão de fazer algo específico, o que materializa na missão da instituição. Drucker (2012) argumenta que, se levarmos em consideração que todas as outras tarefas da instituição são incomuns, apenas as empresas têm missão específica de produzir resultados econômicos. Outras instituições, como igrejas, hospitais, universidades ou forças armadas possuem restrição, enquanto para as organizações de negócios o desempenho econômico é razão e também o propósito da instituição. A primeira definição da administração de empresas é a de ser um órgão econômico específico de uma sociedade industrial.

Assim, todos os atos, todas as decisões, todas as deliberações da Administração têm no desempenho econômico sua primeira dimensão:

Empreendimento de negócios e na tarefa de produzir resultados econômicos.
Embora essa não seja de modo algum a única tarefa a ser executada na
sociedade, trata-se de uma prioridade, pois todas as outras tarefas sociais -
educação, assistência médica, defesa e promoção do conhecimento -
dependem do superávit de recursos econômicos, ou seja, dos lucros e de
outras poupanças, que só podem ser produzidas pelo desempenho
econômico bem-sucedido. Quanto mais ansiamos por essas satisfações,
quanto mais as valorizamos, mais dependemos do desempenho econômico e
das organizações de negócios. (Drucker, 2012, p. 31)

De acordo com o autor ela terá fracassado se não melhorar ou, ao menos, mantiver a capacidade de produção de riqueza dos recursos econômicos que lhe forem confiados para oferecer aquilo que as pessoas esperam. $E$ isso vale para qualquer que seja a estrutura econômica ou política da sociedade: significa responsabilidade pela lucratividade ou resultado. Nesse sentido Drucker indica a lucratividade como ponto fundamental para os objetivos de uma empresa. Mas há também as organizações que não visam lucros.

Para Dias Sobrinho (2003) a responsabilidade social da instituição constitui-se especialmente no que se refere a sua contribuição em relação à inclusão social, no desenvolvimento econômico, na defesa do meio ambiente, da memória cultural, da produção artística e do patrimônio cultural, como descrito nos indicadores desse eixo do Sinaes. Como já apresentado neste texto, na ciência da Administração, missão e objetivos não se referem apenas ao empreendimento de negócios e à tarefa de produzir resultados econômicos. Embora esta seja uma prioridade todas as outras tarefas sociais educação, assistência médica, defesa e promoção do conhecimento - dependem do superávit de recursos econômicos, ou seja, dos lucros e de outras poupanças, que só podem ser produzidas pelo desempenho econômico bem sucedido (Drucker, 2012). 
Portanto, dependemos do desempenho econômico e das organizações de negócios para os benefícios sociais de que necessitamos.

Podemos observar que, na missão institucional e metas e objetivos do PDI, no eixo Desenvolvimento institucional do Sinaes e missão e objetivos e responsabilidade social (Drucker, 2012), as convergências estão nos fundamentos do termo missão, tanto para as organizações do mercado, quanto para instituições de ensino, o qual congrega as demais, ou seja, os objetivos que, por sua vez, definem a responsabilidade social.

O primeiro indício desse vínculo na gestão da educação e na gestão das demais organizações pode ser apontado no modo como passaram a tratar as instituições de ensino após o movimento de reforma iniciado no final da década de 1990: como organização, conforme pesquisado por Lícínio Lima (2011), que analisa, a partir da perspectiva sociológica, essa tendência de tratar a instituição de ensino, principalmente a pública, como organização educativa a serviço do novo modelo produtivo. Assim,

ao eleger a racionalidade econômica, a otimização, a eficácia e a eficiência, como elementos nucleares, os programas de modernização têm tomado por referência privilegiada a atividade econômica, a organização prodrutiva e o mercado, exportando a ideia de empresa para o seio da administração pública. (Lima, 2011, p. 130)

A missão é uma palavra básica nas teorizações da Administração, independentemente do modelo de organização. A missão é fator preponderante no PDI e nos projetos pedagógicos, pois representa o propósito da IES. Conforme o portal do MEC o Plano de Desenvolvimento Institucional consiste num documento em que se definem a missão da instituição de ensino superior e as estratégias para o cumprimento desta missão. O PDI deve considerar a missão, os objetivos e as metas da instituição, bem como as demais propostas de desenvolvimento das suas atividades.

Para Drucker (2012) a responsabilidade social pode ser considerada como uma área em que a empresa decide qual será seu papel na sociedade, estabelece seus objetivos sociais, suas metas de desempenho e de influências na sociedade onde atua. Está relacionada como a empresa responde aos seus fornecedores, clientes, concorrentes, e ao meio ambiente econômico e social no qual opera. A responsabilidade social é assim evidenciada como uma categoria que perpassa, tanto as dimensões do Sinaes, quanto as dimensões da Administração.

Drucker (2012) aponta que as organizações de negócios, e também as instituições de serviços públicos, são órgãos da sociedade e que não existiriam por si mesmas. Ao contrário, existem para fazer algo para a sociedade, um papel específico para atender a uma necessidade da sociedade, da comunidade ou até de grupos específicos:

Nenhuma de nossas instituições existe por si mesma e nem tem um fim em si mesma. Todas são um órgão da sociedade e existem para o bem da sociedade. Os negócios não são exceções. A livre empresa não se justifica por ser boa para os negócios. Ela só pode justificar-se por ser boa para a sociedade. (Drucker, 2012, p. 32)

De acordo com Drucker (2012) nenhuma instituição pode existir fora de uma comunidade ou da sociedade, pois, sob pontos psicológicos, geográficos, culturais e sociais, as instituições devem ser parte de uma comunidade. Nas palavras do autor, "para 
desincumbir-se de sua missão, para produzir bens e serviços econômicos, o empreendimento de negócios deve exercer impacto sobre as pessoas, as comunidades e a sociedade" (p. 33). Na percepção do autor todas as instituições têm uma função dentro da sociedade, têm uma tarefa a ser cumprida para o todo da sociedade e é nesse intuito que a instituição deve ter poder e autoridade sobre pessoas, por exemplo, os empregados, cujos próprios fins e propósitos não são definidos pela empresa de dentro dela. O autor refere-se ao "todo social" (p. 33), ao que esta empresa poderá fazer para a sociedade, quais valores essa empresa agregará para a sociedade e quais valores a sociedade irá agregar a esta empresa.

Assim, a missão institucional de uma IES, bem como o PDI e a responsabilidade social, podem ser considerados como indicadores de qualidade, os quais fazem parte das funções estratégicas, enquanto instituição de ensino ou como organização, independentemente de ser pública ou privada, e são avaliados pelo MEC nos processos de credenciamento e recredenciamento de cursos. No próprio projeto pedagógico do curso, esses indicadores são considerados no processo de avaliação e compõem a nota do curso. Isso quer dizer que, da mesma forma que a universidade se preocupa com a formação técnico-científica de seus alunos, deve se preocupar também com a percepção que está tendo a sociedade em relação às suas ações sociais, daí a dimensão observação da sociedade e o atendimento, tanto no Sinaes, quanto na Administração.

Dessa forma, com base em Drucker (2012), podemos observar que tanto no Sinaes, quanto na Administração existe o dever social, o qual traz responsabilidades para as instituições com a sociedade em que estas se inserem, não podendo levar como social algo imposto pelo Estado, mas o que é espontâneo e com previsões de benefícios sociais que devem ser seguramente respeitados e definidos como mecanismos de desenvolvimento institucional. Tendo em vista que a instituição justifica a sua inserção na sociedade, portanto, seu desenvolvimento é refletido.

\section{Eixo 3 - Categorias em convergência: Informação, atendimento, relação com o cliente}

Quadro 3 -

Interfaces entre as dimensões do Sinaes e da Administração.

\begin{tabular}{|c|c|c|}
\hline \multicolumn{3}{|c|}{ Eixo 3: Informação, atendimento, relação } \\
\hline Sinaes & Administração & Convergência \\
\hline Políticas Acadêmicas & $\begin{array}{l}\text { Políticas de Desenvolvimento } \\
\text { de Tecnologias }\end{array}$ & Políticas de tecnologias \\
\hline $\begin{array}{lcc}\text { Políticas para } 0 & \text { ensino, } \\
\text { pesquisa e extensão. } & \end{array}$ & $\begin{array}{lrr}\text { Políticas } & \text { para } & 0 \\
\text { desenvolvimento de } & \text { novas } \\
\text { tecnologias } & & \\
\end{array}$ & $\begin{array}{l}\text { Políticas de tecnologias de } \\
\text { desenvolvimento institucional }\end{array}$ \\
\hline $\begin{array}{l}\text { Políticas de atendimento aos } \\
\text { discentes }\end{array}$ & $\begin{array}{l}\text { Políticas de atendimento ao } \\
\text { cliente, fornecedores } \\
\text { colaboradores. }\end{array}$ & Políticas de atendimento \\
\hline $\begin{array}{l}\text { Políticas de observação e } \\
\text { comunicação com a sociedade }\end{array}$ & Observação da sociedade. & Políticas de relacionamento \\
\hline
\end{tabular}


No eixo 3, intitulado Políticas Acadêmicas do Sinaes, estão congregadas três dimensões, a saber: 1) Políticas para ensino, pesquisa, extensão e pós-graduação; políticas de observação e de comunicação com a sociedade; políticas de atendimento aos discentes. Conforme documento do Sinaes, as políticas acadêmicas abrangem tudo que se refere ao ensino, à pesquisa e extensão e à pós-graduação. $\mathrm{Na}$ textualidade das dimensões da Administração até os termos utilizados são os mesmos ou idênticos: políticas; atendimento; discentes equivalendo a clientes; observação sociedade.

Neste trabalho todas as políticas e ações que envolvem a parte acadêmica estão sendo interpretadas como novas tecnologias de desenvolvimento, tomando emprestado o suporte teórico de Ball (2014) e Drucker (2012). Assim, cabe frisar que as políticas para o desenvolvimento de tecnologias não se trata de tecnologia em si, mas a política para o desenvolvimento de novas tecnologias. A quantidade de computadores nas escolas ou 0 sistema operacional a ser utilizado são temas secundários. $O$ que conta é o uso da tecnologia de modo imaginativo para a produção de conhecimento e serviços.

Nesta discussão entendemos que essa definição explica o uso do termo Políticas nessas dimensões em análise. Recorrendo a Ball (2014), no conceito sociológico de Política em movimento, teorizado pelo autor como fluxos, capital, ideias, entre outros, e mobilidades entre estruturas sociais e pessoas o sentido de política, podem ser aqui interpretados como relações entre a instituição ou organização e a sociedade, o mercado, o conhecimento, a pesquisa, o exercício da cidadania, entre outras. Para Ball (2014),

redes de políticas são um tipo de "social" novo, envolvendo tipos específicos de relações sociais, de fluxos e de movimentos. Eles constituem comunidades de políticas, geralmente baseadas em concepções compartilhadas de problemas sociais e suas soluções. (p. 68)

Nesse sentido é possível observar na lei n. 10.861, de 2004, que se constituem políticas acadêmicas: políticas de ensino e ações acadêmico-administrativas para os cursos de graduação; políticas de ensino e ações acadêmico-administrativas para os cursos de pós-graduação stricto sensu; políticas de ensino e ações acadêmicoadministrativas para os cursos de pós-graduação lato sensu; políticas institucionais e ações acadêmico-administrativas para a pesquisa ou iniciação científica, tecnológica, artística e cultural; políticas institucionais e ações acadêmico-administrativas para a extensão; políticas institucionais e ações de estímulo relacionadas à difusão das produções acadêmicas: científica, didático- pedagógica, tecnológica, artística e cultural; comunicação da IES com a comunidade externa; comunicação da IES com a comunidade interna; programas de atendimento aos estudantes; programas de apoio à realização de eventos internos, externos e à produção discente; política e ações de acompanhamento dos egressos; atuação dos egressos da IES no ambiente socioeconômico; inovação tecnológica e propriedade intelectual: coerência entre o PDI e as ações institucionais.

Já no caso da Administração o eixo intitulado Políticas de desenvolvimento de tecnologias engloba as seguintes dimensões: políticas para o desenvolvimento de novas tecnologias; políticas de observação da sociedade; políticas de atendimento aos clientes, 
fornecedores e colaboradores. Cabe destacar que Drucker (2012) não divide essas duas últimas dimensões, mas, para este trabalho, optou-se por essa divisão a fim de se adequar aos cinco eixos do Sinaes, o que, para efeito desta análise, neste trabalho, metodologicamente facilita a interpretação.

No que se refere às políticas de atendimento aos estudantes propostas pelo Sinaes, analisam-se as formas com que os estudantes estão sendo integrados à vida acadêmica e os programas pelos quais a IES busca atender aos princípios inerentes à qualidade de vida estudantil. No que se refere às políticas de ensino e de extensão as respectivas formas de operacionalização, incluídos os procedimentos para estímulo ao desenvolvimento do ensino, a produção acadêmica e das atividades de extensão, explicitam as políticas de formação acadêmico-científica, profissional e cidadã, de construção e de disseminação do conhecimento, de articulação interna, que favorecem a iniciação científica e profissional de estudantes, os grupos de pesquisa e o desenvolvimento de projetos de extensão.

Relativamente às dimensões da Administração Drucker (2012) afirma que é necessário ouvir as necessidades dos resultados colhidos nesta ferramenta para implantar políticas para $o$ atendimento. Os clientes permeiam de fornecedores a colaboradores. Todos devem ter um bom atendimento para que esses valores sejam agregados à imagem institucional. $\mathrm{O}$ autor chama a atenção para a necessidade de se olhar para a sociedade. A observação social é imprescindível, pois a sociedade muda, as tecnologias mudam, e se a instituição não estiver atenta às exigências da sociedade poderá deixar de cumprir seu papel social e, até mesmo, deixará de ser útil e, como consequência, deixará de existir.

Dessa forma, as políticas de atendimento aos clientes podem ser compreendidas na relação com as políticas de atendimento aos clientes, fornecedores e colaboradores do campo da administração. O termo atendimento é definido por Carpinetti (2008) como satisfação das necessidades e das expectativas dos clientes, proporcionando serviços e produtos de qualidade para a sociedade. Para o autor o atendimento deve ser focado no alcance da satisfação dos indivíduos que utilizam tal serviço. Esse atendimento poderá até gerar melhoria, pois é neste sentido que uma empresa deve se alicerçar, na melhoria do atendimento, inclusive as instituições de ensino.

Drucker (2012) afirma que há um século as pessoas ainda estavam nas fazendas arando a terra. Os artífices trabalhavam sozinhos ou com um ou dois ajudantes. Quase ninguém trabalhava em organizações, exceto padres, militares, professores, grupos muito pequenos. Mas com o fordismo isso acabou. Não era mais preciso ter habilidade para trabalhar. A partir daí as pessoas só conseguiam ser produtivas pertencendo a organizações. Drucker (2012) afirma que a Revolução Industrial aplicou o conhecimento às máquinas, a revolução da produtividade de Frederick Taylor aplicou conhecimento ao trabalho e a revolução gerencial de meados do século 20 aplicou conhecimento ao conhecimento. A continuidade desse processe é que está moldando a nova sociedade: aplicação contínua de conhecimento novo ao que já se conhece.

Assim, a quantidade de computadores nas escolas ou o sistema operacional a ser utilizado são temas secundários. O que conta é o uso da tecnologia de modo imaginativo. Drucker (2012) salienta, ainda, que a administração precisa executar três tarefas, 
igualmente importantes, mas essencialmente diferentes a fim de criar condições para que a instituição funcione e contribua: existir dentro de uma sociedade, ter como foco a gestão financeira e a gestão dos impactos sociais:

Cada vez mais, em nossa sociedade pluralista, com múltiplas organizações, a empresa deve incluir entre seus fundamentos não só o interesse pelos aspectos quantitativos da vida, isto é, bens e serviços econômicos, mas também o zelo pelos aspectos qualitativos da vida, ou seja, pelo ambiente físico, humano e social das pessoas modernas e da comunidade moderna. (Drucker, 2012, p. 33)

Nesse contexto, a observação da sociedade é, na percepção de Drucker (2012) inerente a todas as instituições, sejam elas universidades, hospitais e órgãos públicos, pois também produzem impactos e também têm responsabilidades. Da mesma forma é também inerente ao trabalho de todos os gestores. Relativamente a essa dimensão o autor relata que, cada vez mais, recorre-se à administração das empresas, tanto em busca de liderança, quanto da qualidade de vida social e afirma que as instituições devem garantir a produtividade do trabalho e a capacidade de realização dos trabalhadores, assim como gerenciar os impactos sociais e as responsabilidades sociais.

Diante do exposto é possível observar que, tanto uma instituição de educação, quanto uma organização de outras áreas do mercado tem o dever de olhar para a sociedade, para a prosperidade social e também para o meio, a fim de descobrir de que a sociedade necessita que possa oferecer à sociedade com vistas à prosperidade da empresa e também à prestação de serviço responsável. Assim, a dimensão comunicação com a sociedade identifica as formas de aproximação efetiva entre IES e sociedade, de tal sorte que a comunidade participe da vida da IES, bem como a esta se comprometa com a melhoria das condições de vida da comunidade, ao repartir com ela o saber que produz e as informações que detém.

É possível concluir que a comunicação, o atendimento e a relação com a sociedade constituem um olhar social que tem como função principal o olhar cognitivo do conjunto de sinais que vem da sociedade (Liker, 2007) e, ao mesmo tempo, o olhar social representa a visão que a empresa tem sobre a sociedade, podendo o atendimento ser considerado como um dos mecanismos de aproximação social. A empresa ou instituição educacional não estão à deriva da sociedade, ao contrário, compõem a sociedade e, como afirma Hino (2009), devem olhar para a sociedade e encontrar mecanismos para ouvir e ser ouvida.

\section{Eixo 4 - Categorias em convergência: Políticas de gestão}

Quadro 4 -

Interfaces entre as dimensões do Sinaes e da Administração.

\begin{tabular}{|l|l|l|}
\hline \multicolumn{1}{|c|}{ Eixo 4: Políticas de gestão } \\
\hline Políticas de gestão & \multicolumn{1}{|c|}{ Administração } & \multicolumn{1}{c|}{ Convergência } \\
\hline $\begin{array}{l}\text { Políticas de Pessoal, planos } \\
\text { de carreira. }\end{array}$ & Políticas de gestão & Políticas de gestão \\
\hline $\begin{array}{l}\text { Sustentabilidade financeira e Pessoal; } \\
\text { econômica }\end{array}$ & $\begin{array}{l}\text { Organização e Gestão da } \\
\text { Instituição }\end{array}$ & $\begin{array}{l}\text { Políticas de administração } \\
\text { (financeira, econômica, } \\
\text { administrativa) }\end{array}$ \\
\hline
\end{tabular}


O eixo 4, Políticas de gestão, congrega três dimensões do Sinaes e da Administração, quais sejam: políticas de gestão, políticas de pessoal, políticas de administração. As três são convergentes até mesmo em nomenclatura, como se observa acima. Portanto, procuramos trazer à discussão as políticas de pessoal e de carreira, a sustentabilidade financeira e econômica, todas incluídas em uma dimensão maior denominada Políticas de gestão, considerando-se que no eixo Políticas de gestão o Sinaes tem um olhar para a gestão das instituições, um olhar para dentro, focando as políticas de pessoal, seu plano de carreira, e as políticas voltadas para a organização e para a gestão da IES, inclusive com preocupação voltada para sua saúde financeira e, consequentemente, para a sustentabilidade.

No que se refere às políticas de pessoal para o Sinaes incluem-se: as carreiras do corpo docente e do corpo técnico administrativo, seu aperfeiçoamento, desenvolvimento profissional e suas condições de trabalho. As políticas e os programas de formação, de aperfeiçoamento e de capacitação do pessoal docente e técnico administrativo, associando com planos de carreira condizentes com a magnitude das tarefas a serem desenvolvidas e com condições objetivas de trabalho.

Quanto à administração incluem-se: a evolução dos profissionais na empresa, o que só pode ser feito por meio de planos de carreira, muitas vezes materializados por planos de cargos e de salários. Segundo Drucker (2012) isso irá motivar o colaborador a produzir mais e a projetar seus ideais dentro da empresa, pois, como destaca o autor, a lógica dos seres humanos é radicalmente diferente da lógica do trabalho:

Organizar o trabalho de acordo com a própria lógica do trabalho é apenas o primeiro passo. O segundo, muito mais difícil, é tornar o trabalho adequado para seres humanos. E a lógica dos seres humanos é radicalmente diferente da lógica do trabalho. Garantir a capacidade de realizações dos trabalhadores implica considerar o ser humano como organismo, com propriedades fisiológicas e psicológicas, com capacidades e limitações peculiares e com um modo de ação distinto. Implica considerar os recursos humanos como seres humanos, não como coisas, dotados - ao contrário de outros recursos - de personalidade, de cidadania, de controle sobre se trabalham, sobre o quanto trabalham e sobre quão bem trabalham e, portanto, exigindo responsabilidade, motivação, participação, incentivos e recompensas, liderança, status e função. (Drucker, 2012, p. 31)

Conforme analisa Cária (2015) essa corrente está baseada na psicologia organizacional e, assim, redimensiona e atualiza conceitos da teoria das relações humanas: introduz a ideia de que administrar requer mais do que exercícios e funções básicas de gerência como planejar, organizar e controlar. Essa teoria traz novo conceito de administração que passa a ser entendido como a coordenação de diferentes atividades de contribuintes individuais com a finalidade de efetuar transações planejadas com o ambiente. Seus principais enfoques são a mudança organizacional com planejamento e a abordagem de sistema aberto, visando a facilitar o crescimento e o desenvolvimento das organizações com a aplicação das ciências do comportamento. Nessa mesma linha de reflexão Chiavenato (2000) afirma que ênfase nas pessoas exige observações específicas nas necessidades de cada empregado para que ele possa produzir mais e melhor. Tratase de observar as necessidades fisiológicas, as necessidades de segurança, as 
necessidades sociais, as necessidades de estima, as necessidades de autorrealização. Portanto, quando Sinaes prevê avaliar as políticas de gestão implantadas pelas IES é preciso entender que não se trata apenas de administração, mas de algo mais amplo e complexo. Daí cabe buscar fundamentos sobre o termo gestão.

Um estudo realizado por Cária (2015) revela que o termo gestão passou a ocupar espaço cada vez maior no processo de administração das organizações e chegou também às instituições de ensino, muitas vezes interpretado como sendo a mesma coisa. A autora destaca o conceito de gestão cunhado por Drucker (2012), management, traduzido no Brasil como gestão. Drucker (2012) corrobora gestão é o processo que visa a atingir os objetivos e as metas de uma organização, de forma eficiente e eficaz, por meio de organização, de planejamento, de liderança e de controle dos recursos disponíveis.

Nesse sentido, gestão trata-se de um conjunto de normas e de funções para disciplinar elementos de produção, incluindo todos os recurso, inclusive as pessoas, tendo como objetivo alcançar um resultado eficaz e um retorno financeiro. Portanto, gerir envolve a elaboração de planos, pareceres, relatórios, projetos, ações e estratégias que envolvem a aplicação de conhecimentos específicos. Para Drucker, são várias as áreas da gestão: financeira: de produção: de administração pública: de materiais: de marketing: de gestão de pessoas: de gestão sistêmica: de sistemas de informação: de organização: de sistemas e métodos e de comércio internacional.

Como ressalta Cária (2015), nas ideias desenvolvidas por Peter Drucker a gestão não está voltada para os meios: ela tem seu enfoque principal nos resultados, sendo preciso haver métricas que permitam avaliar esses resultados. Drucker é categórico ao defender que gestão traz a ideia principal de resultado, ou seja, o foco da gestão é o resultado, comprovado por meio de indicadores e de mecanismos de avaliação. Assim, de acordo com o criador da ideia de gestão, os resultados estão fora da empresa e não dentro, pois vêm do aproveitamento de oportunidades e não da resolução de problemas.

Concluindo, podemos observar a migração da teoria do comportamento organizacional para a teoria do desenvolvimento organizacional, ou seja, a instituição precisa olhar para as pessoas, porém deverá assegurar o desenvolvimento financeiro, planejando seu crescimento e continuidade das atividades. Daí a importância dos planos de carreira e de outras políticas de pessoal. De acordo com Chiavenatto (2010) carreira é o gerenciamento da vida de pessoas nas instituições.

A Administração sempre deve conjugar suas ações em dois tempos: o presente e o futuro. Precisa assegurar o desempenho da instituição presente ou não haverá possibilidade de futuro. Porém, deve gerir sua capacidade de operar, de crescer e de mudar para o futuro, do contrário, fechará suas portas. O planejamento confere à decisão gerencial características especiais. É o ato pelo qual os gestores deverão integrar ou harmonizar o presente com o futuro.

Da mesma forma, pelo olhar das dimensões da Administração (Drucker, 2012), como um processo em cadeia, tendo essas políticas concretizadas, espera-se garantir a sustentabilidade financeira da instituição, sendo que esta somente tem sentido, em vista do significado social que é a razão de existência de toda IES. É a sustentabilidade que permite a continuidade dos compromissos na oferta da educação superior, avalia a capacidade de gestão e de administração do orçamento e as políticas e estratégias de 
gestão acadêmica com vistas à eficácia na utilização e na obtenção dos recursos financeiros necessários ao cumprimento das metas e das prioridades estabelecidas. Como já mencionado, Drucker (2012) teoriza que a administração de empresas, em todas as decisões e ações, deve considerar em primeiro plano o desempenho econômico e financeiro. Afirma, ainda, que a justificativa da existência de uma empresa são os bons resultados econômicos que ela produz, a priori, uma vez que, sem essa condição, os demais benefícios sociais não poderão ser atendidos.

Nesse sentido, cabe ainda frisar a importância de políticas de gestão responsáveis que considerem os diversos fatores aqui já apresentados, como a relação com a sociedade e o atendimento ao cliente, pois, se o foco de uma empresa é se propagar no tempo, para isso deverá ter segurança financeira, uma vez que está em jogo não apenas a vida, pessoal ou profissional, do empresário ou do reitor/gestores, mas, sim, as condições de vida da sociedade, tomando esta como um conjunto de pessoas em interação, cujos elementos compartilham propósitos, gostos, costumes, preocupações e ideais. Da mesma forma que uma empresa forma uma rede de negócios, esta rede depende do todo, pois, se falhar em algum lugar poderá prejudicar o todo, que é o resultado, tendo em vista sua missão e o planejamento. Nessa complexa dimensão fazemos relação com o compromisso político e social de toda IES, o que justifica o fundamento do dispositivo do Sinaes em por a vida financeira de uma instituição de ensino como dimensão no processo de avaliação, deixando explícita a preocupação com a segurança do aluno e, dessa forma, também contribuindo com o processo de gestão.

\section{Eixo 5: Infraestrutura física versus infraestrutura física e recursos para desenvolver tarefas}

Relativamente ao Sinaes o eixo infraestrura física, especialmente no que se refere ao ensino, à pesquisa e à extensão, a ênfase da avaliação recai sobre a biblioteca; sobre os recursos de informação e de comunicação; sobre os recursos de informática, como laboratórios; sobre a acessibilidade; sobre condições de trabalho para os profissionais e sobre condições de sala aula; sobre condições que facilitem as relações com a comunidade, entre outros. Enfim, trata-se da infraestrutura da instituição, relacionando-a com as atividades acadêmicas de formação, de produção e de disseminação de conhecimentos e com as finalidades próprias da IES.

No que se refere à dimensão infraestrutura, em qualquer organização, Drucker (2012) ressalta que o foco deve estar nas necessidades dos recursos humanos da empresa. Portanto, cabe ao gestor desenvolver processos eficientes para a contratação, para o treinamento, para a avaliação, para a premiação, para a promoção e para o gerenciamento do fluxo de colaboradores na organização. Em seu conjunto, o autor caracteriza como estrutura organizacional, sendo que tal estrutura deve ser pensada pelo administrador na direção de fornecer condições para que a empresa possa otimizar os processos, visando à eficiência administrativa. A fim de contribuir com essa interpretação, recorremos a Liker (2009), que define infraestrutura na empresa como um conjunto de elementos estruturais que impulsiona o desenvolvimento institucional e viabiliza sua atividade. 
A lei do Sinaes, n. 10.861/2004, justifica a necessidade de infraestrutura para favorecer aos serviços prestados pela instituição, o que estamos entendendo como idêntico ao que teoriza Drucker (2012), quando este argumenta que a infraestrutura e os recursos para o desenvolvimento de tarefas são fundamentais para a vida de uma instituição. Portanto, vislumbra-se a necessidade de infraestrutura, aqui entendida como material e humana, tanto para instituições de ensino, com suas finalidades específicas, quanto para qualquer empresa ou organização, também com suas finalidades particulares.

Por fim, ao concluir a discussão das dez dimensões, com foco nas interfaces que revelam os vínculos administrativos que apontam para a melhoria e para o controle de qualidade tanto da educação, quanto de instituições de administração, cabe destacar que o que está em discussão é qualidade dos serviços prestados à sociedade. Foi possível identificar convergências explícitas em relação ao dispositivo do Sinaes ao ser este relacionado com as dimensões da administração. Assim, apesar da polissemia do termo qualidade, entendemos importante apresentar na subseção seguinte algumas discussões sobre qualidade na educação.

\section{Considerações finais}

Ao chegar às considerações finais é possível observar que algumas questões levaram à implantação de normas e de dispositivos legais para o controle da qualidade da educação superior. Como demonstrado no trabalho, no contexto de necessidade de expansão do ensino superior foram implantadas políticas para ampliação do número de IES e de matrículas, com a participação do setor privado. Apesar dos resultados positivos obtidos em face ao se propôs, por outro lado, sobressaiu a questão da falta de qualidade de ensino, o que levou o governo a interferir para sanar, ou pelo menos amenizar, este problema.

Seguindo modelos internacionais a forma escolhida foi o aumento de mecanismos de fiscalização, por meio principalmente da avaliação. Como não há uma concepção única de avaliação, as interpretações e os discursos daí originados apresentam diversos vieses, mas, observa-se a predominância de uma concepção de avaliação institucional configurada como política pública, com finalidades formativas, mas contraditoriamente, meritocrática.

O perfil do modelo de avaliação instituído no Brasil, institucionalizado pelo Sinaes, revela uma política de avaliação vinculada a forma de controles e fiscalização, na direção administrativa, fazendo da avaliação um instrumento de coleta de informações e dados para alimentar e fundamentar as decisões no âmbito da regulação da educação superior, ou seja, da oferta, da qualidade e da expansão.

A complexidade que tomou o processo de avaliação da educação superior pode ser atribuída às dimensões que a avaliação procura alcançar, quando o governo, por meio de seus órgãos avaliadores, toma para si decisões como as que tratam da autorização de instituições, credenciamento e recredenciamento de instituições; autorização e reconhecimento de cursos; renovação de recredenciamento de cursos superiores; 
avaliação de cursos e instituições, entre outros. Nesse contexto, a tarefa da avaliação torna-se centralizadora e imprescindível como fornecedora de dados e informações científicas e confiáveis sobre as atividades desenvolvidas pelas instituições de ensino superior para a regulação, gerando tensões e polêmicas entre avaliação e regulação.

Diante da complexidade assumida pela avaliação institucional na universidade, compreendeu-se que suas raízes têm origem no próprio fenômeno da avaliação e também no objeto que está sendo avaliado ou regulado, que é prioritariamente, a qualidade dos serviços educacionais prestados. Haja vista a polissemia do termo qualidade e as múltiplas funções que a sociedade contemporânea espera das instituições de ensino, compreender as dimensões do Sinaes como uma forma de regulação da oferta da educação superior exigiu ampliar o olhar para além do restrito cenário educacional, seguindo as próprias características do modelo avaliativo adotado, predominante, administrativas.

É neste cenário que o Sinaes foi compreendido neste trabalho, pois, como demonstrado no processo de análise, esse foi o formato administrativo para garantir uma política de regulação da qualidade da educação superior no Brasil, embora sobre prerrogativas da avaliação formativa, portanto, pedagógicas.

Como demonstrado na seção na Análise e discussão, as dimensões do Sinaes parecem espelhar-se nas dimensões da Administração, propostas por Drucker (2012), embora não tenhamos entrado em contato com nenhum estudo já realizado nesse sentido. As aproximações são muito diretas: visualiza-se nos eixos do Sinaes e nas suas dez dimensões que cada uma delas engloba a nítida semelhança com os processos de gestão na perspectiva de Drucker (2012). O autor entende a gestão de qualquer organização ou instituição como um processo dinâmico que vai além da Administração.

Como dimensionado na lei n. 10.861 de 2004, o Sinaes é um dispositivo em constante processo de aprimoramento. Isso tem sido comprovado diante das contínuas publicações de decretos, de normas, de portarias e de pareceres, os quais estabelecem e orientam procedimentos que as IES devem realizar, pois serão avaliados para credenciamento e para recredenciamento de cursos, bem para medir o nível de qualidade de curso. É possível concluir que existe um processo de tensão entre avaliação institucional, regulação e gestão das instituições de ensino e que, embora sejam processos distintos, eles se encontram imbricados.

Por fim, a partir deste trabalho de análise, cabe considerar que, enquanto parte constitutiva do projeto de reforma do ensino superior, a avaliação assume papel central de regulação para a melhoria da educação no Brasil. Por meio da avaliação o governo passou a utilizar os resultados educacionais como base para o diagnóstico e para 0 aprofundamento de questões da educação, tendo a política de avaliação do Sinaes, junto com a combinação de critérios científicos de avaliação, como indicadores de gestão e de qualidade dos serviços educacionais prestados à sociedade.

É possível dizer que há uma nítida relação do modelo avaliativo proposto pelo MEC, por meio do Sinaes, com a dimensão administrativa das instituições de ensino superior. Como apresentado na análise dos eixos de convergências entre as dimensões do Sinaes (MEC) e as dimensões da Administração (Drucker, 2012), as dimensões do processo de 
avaliação vão encontro das características do modelo de gestão preconizado por Drucker (2012), principalmente, pelo foco das ações e estratégias no planejamento e nos resultados, mas preocupado com o caráter humano que perpassa essas entidades, sejam as organizações ou instituições educacionais.

De acordo com Drucker a realização de qualquer administração depende de resultados e são os resultados que transformam a Administração. Portanto, diante do mundo atual é necessário não olhar apenas para a excelência técnica, tampouco só por responsabilidade moral ou pelas relações humanas, pois a ciência da Administração e a administração científica, bem como a economia gerencial e as relações humanas, deverão integrar-se e unificar-se na teoria e na prática da gestão.

\section{Referências}

ANTUNES, Antonio Lobo. As naus. Lisboa: Dom Quixote, 1988.

ABRAMOWICZ, Mere Políticas públicas de avaliação: uma pesquisa em currículo. Curitiba: CRV, 2010.

AFONSO, Almerindo Janela. Reforma do estado e políticas educacionais: entre a crise do estado-nação e a emergência da regulação supranacional. Revista Educ. Soc., Campinas, v. 22, n. 75, 2010, p. 15-32.

BARDIN, Laurence. Análise de conteúdo. Lisboa: Edição 70, 2009.

BARREYRO, Gladys Beatriz; ROTHEN, José Carlos. Sinaes contraditórios: considerações sobre a elaboração e implantação do Sistema Nacional de Avaliação da Educação Superior. Revista Educação \& Sociedade, v. 27, n. 96, 2006, p. 955-977.

BRASIL. Presidência da República. Decreto n. 19.851, de 11 de abril de 1931. Dispõe que o ensino superior no Brasil obedecerá, de preferência, ao sistema universitário, podendo ainda ser ministrado em institutos isolados, e que a organização técnica e administrativa das universidades é instituída no presente Decreto, regendo-se os institutos isolados pelos respectivos regulamentos, observados os dispositivos do seguinte Estatuto das Universidades Brasileiras. Portal Planalto. Brasília, DF. Disponível em http://www.planalto.gov.br/ccivil 03/decreto/1930-1949/D19851.htm>. Acesso em 20 jun. 2015.

BRASIL. Presidência da República. Lei n. 378, de 13 de janeiro de 1937. Dá nova, organização ao Ministério da Educação e Saúde Publica. Portal Planalto. Brasília, DF. Disponível em <https://www.planalto.gov.br/ccivil 03/leis/1930-1949/10378.htm>. Acesso em 20 jun. 2015.

BRASIL. Presidência da República. Lei n. 4.024, de 20 de dezembro de 1961. Fixa as Diretrizes e Bases da Educação Nacional. Portal Planalto. Brasília. http://www.planalto.gov.br/ccivil 03/Leis/L4024.htm>. Acesso em 20 jun. 2015.

BRASIL. Presidência da República. Decreto n. 91.177, de 29 de março de 1985. Institui a Comissão Nacional visando à reformulação da educação superior e dá outras providências. Portal Câmara dos Deputados. Brasília. Disponível em http://www2.camara.leg.br/legin/fed/decret/1980-1987/decreto-91177-29-marco-1985441184-publicacaooriginal-1-pe.html>. Acesso em 18 jun. 2015.

BRASIL. Ministério da Educação. Secretaria de Ensino Superior. Programa de Avaliação Institucional das Universidades Brasileiras. Brasília: Sesu, 1994. Disponível em: http://www.dominiopublico.gov.br/download/texto/me002072.pdf >. Acesso em 15 out. 2015. 
BRASIL. Ministério da Administração e Reforma do Estado (MARE). Câmara da Reforma do Estado. Plano Diretor da Reforma do Aparelho de Estado (PDRAE). Brasília, DF, 1995. Disponível em <http://www.bresserpereira.org.br> Acesso em 11 nov. 2015.

BRASIL. Presidência da República. Decreto 9131, de 24 de novembro de 1995. Altera dispositivos da Lei n.4.024, de 20 de dezembro de 1961, e dá outras providências. Portal Planalto. Brasília. Disponível em <http://www.planalto.gov.br/CCIVIL 03/leis/L9131.htm>. Acesso em 20 jun. 2015.

BRASIL. Presidência da República. Lei n. 9.448, de 14 de março de 1997b. Transforma o Instituto Nacional de Estudos e Pesquisas Educacionais - INEP em Autarquia Federal, e dá outras providências. Portal Planalto. Brasília. Disponível em $<$ http://www.planalto.gov.br/cciVil 03/LEIS/L9448.htm >. Acesso em 20 jun. 2015.

BRASIL. Presidência da República. Lei n. 10.709, de 31 de julho de 2003. Acrescenta incisos aos arts. 10 e 11 da Lei ${ }^{\circ} 9.394$, de 20 de dezembro de 1996, que estabelece as diretrizes e bases da educação nacional e dá outras providências. Portal Planalto. Brasília. Disponível em <http://www.planalto.gov.br/ccivil 03/leis/2003/10.709.htm>. Acesso em 28 maio 2015.

BRASIL. Presidência da República. Lei n. 10.861, de 14 de abril de 2004. Institui o Sistema Nacional de Avaliação da Educação Superior - SINAES e dá outras providências. Portal Planalto. Brasília. Disponível em < http://www.planalto.gov.br/ccivil 03/ ato20042006/2004/lei/l10.861.htm>. Acesso em 20 jun. 2015.

BRASIL. Presidência da República. Decreto n. 5.622, de 19 de dezembro de 2005a. Regulamenta o art. 80 da Lei n. 9.394, de 20 de dezembro de 1996, que estabelece as diretrizes e bases da educação nacional. Portal Planalto. Brasília. DF. Disponível em $<$ http://www.planalto.gov.br/ccivil 03/ ato2004-2006/2005/decreto/d5622.htm>. Acesso em: 14 abr. 2015.

BRASIL. Presidência da República. Lei n. 11.183, de 5 de outubro de 2005b. Dá nova redação ao inciso II do caput do art. 20 da lei n. 9.394, de 20 de dezembro de 1996, que estabelece as diretrizes e bases da educação nacional. Portal Planalto. Brasília, DF. Disponível em <http://www.planalto.gov.br/ccivil 03/ Ato20042006/2005/Lei/L11183.htm>. Acesso em 14 abr. 2015.

BRASIL. Presidência da República. Decreto n. 5.773, de 9 de maio de 2006a. Dispõe sobre o exercício das funções de regulação, supervisão e avaliação de instituições de educação superior e cursos superiores de graduação e sequenciais no sistema federal de ensino. Portal Planalto. Brasília. Disponível em $<$ http://www.planalto.gov.br/ccivil 03/ ato2004-2006/2006/decreto/d5773.htm>. Acesso em 18 abr. 2015.

BRASIL. Ministério da Educação. Portaria normativa n. 40, de 12 de dezembro de 2007, alterada pela portaria normativa n. 23 , de $1^{\circ}$ de dezembro de 2010a. Institui o e-MEC, sistema eletrônico de fluxo de trabalho e gerenciamento de informações relativas aos processos de regulação, avaliação e supervisão da educação superior no sistema federal de educação, e o Cadastro e-MEC de Instituições e Cursos Superiores e consolida disposições sobre indicadores de qualidade, banco de avaliadores (Basis) e o Exame Nacional de Desempenho de Estudantes (Enade) e outras disposições. Portal MEC. Disponível em http://portal .mec.gov.br/index.php?option=com docman\&view=download\&alias $=16763$-port-norm040-2007-seres\&category slug=dezembro-2014-pdf\&ltemid=30192>. Acesso em 20 nov. 2015. 
BRASIL. Presidência da República. Lei n. 12.796, de 4 de abril de 2013. Altera a Lei n. 9.394, de 20 de dezembro de 1996, que estabelece as diretrizes e bases da educação nacional, para dispor sobre a formação dos profissionais da educação e dar outras providências. Portal Planalto. Brasília. Disponível em <http://www.planalto.gov.br/ccivil 03/ ato2011-2014/2013/lei//12796.htm>. Acesso em 14 abr. 2015.

BRASIL. Ministério da Educação. Portaria Normativa n. 92, de 31 de janeiro de 2014. Aprova em extrato os indicadores do Instrumento de Avaliação Institucional Externa para os atos de credenciamento, recredenciamento e transformação de organização acadêmica, modalidade presencial, do Sistema Nacional de Avaliação da Educação Superior - Sinaes. Portal Inep. Disponível em <http://portal.inep.gov.br/superioravaliacao institucional-legislacao >. Acesso em 12 jan. 2016.

BRASIL. Ministério da Educação. Portaria Normativa n. 92, de 31 de janeiro de 2014. Aprova em extrato os indicadores do Instrumento de Avaliação Institucional Externa para os atos de credenciamento, recredenciamento e transformação de organização acadêmica, modalidade presencial, do Sistema Nacional de Avaliação da Educação Superior - Sinaes. Disponível em <http://portal.inep.gov.br/superioravaliacao institucional-legislacao >. Acesso em 12 jan. 2016.

BRASIL. Ministério da Educação. Nota técnica Inep/Daes/Conaes n. 062, de 09 de outubro 2015. Define a estrutura do Relato Institucional. Disponível em <http://www.ifsc.educ.br/arquivos/sic/NotaTecnica 62-2014.pdf> Acesso em 12 jan. 2016

BRASIL. Presidência da República. Casa Civil. Subchefia para Assuntos Jurídicos. Lei n. 13.005 de 25 de junho de 2014. Aprova o Plano Nacional de Educação - PNE e dá outras providências, Brasília, 25 jun. 2014.

BRESSER, Luiz Pereira Carlos. A reforma do estado dos anos 90: mecanismos de controle Brasil, 2008. Disponível em <http://www.bresserpereira.org.br/papers/1998/Areforma-dos-anos-90.pdf>. Acesso em 2 mar. 2016.

BURBULES, Nicholas; TORRES, Carlos Alberto. Globalização e educação: uma introdução. In: BURBULES, Nicholas; TORRES, Carlos Alberto (orgs.). Globalização e educação: perspectivas críticas. Porto Alegre: Artmed, 2004, p. 23-53.

CÁRIA, Neide Pena. Gestão da educação em perspectiva comparada com a administração. In: CÁRIA, Neide Pena Gestão educacional e avaliação: perspectivas e desafios contemporâneos. Campinas: Pontes, 2015, p.17-58.

CARPINETTI, Luiz Cesar Ribeira et al. Gestão da qualidade princípios e requisitos. São Paulo: Atlas, 2011.

CATANI, Afrânio Mendez; OLIVEIRA, João Ferreira. Educação superior no Brasil: reestruturação e metamorfose das universidades públicas. Petrópolis: Vozes, 2002.

CATANI, Afrânio Mendez; OLIVEIRA, João Ferreira. A reestruturação da educação superior no debate internacional: a padronização das políticas de diversificação e diferenciação. Revista Portuguesa de Educação, Braga, v. 13, n. 2, 2000, p. 29-53.

CHIAVENATO, Idalberto Gestão de pessoas. São Paulo: Elsevier, 2010.

CHIZZOTTI, Antonio A Pesquisa em ciências humanas e sociais. São Paulo: Cortez, 2008.

Congresso Nacional. Lei n. 9.394, de 20 de dezembro de 1996. Estabelece as diretrizes e bases da educação. Portal Planalto. Brasília. Disponível em < http://www.planalto.gov.br/CCIVIL 03/leis/L9394.htm>. Acesso em 14 abr. 2015. 
CRESWELL, John. Projeto de pesquisa: métodos qualitativo, quantitativo e misto. Porto Alegre: Artmed, 2010.

CUNHA, Antonio Luiz. A universidade reformada: o golpe de 1964 e a modernização do ensino superior. Campinas: Unesp, 2007.

DIAS SOBRINHO José Qualidade, avaliação: do Sinaes a índices. Revista Avaliação, Campinas, v. 13, n. 3, 2008, p. 817-825.

DIAS SOBRINHO, José. Avaliação: Políticas educacionais e reformas da educação superior. São Paulo: Cortez, 2003.

DOURADO, Luiz Fernandes; OLIVEIRA, João Ferreira; CATANI, Afrânio Mendez. Transformações recentes e debates atuais no campo da educação superior do Brasil. In: DOURADO, Luiz Fernandes; CATANI, Afrânio Mendez; OLIVEIRA, João Ferreira. (Orgs.) Políticas e gestão da educação superior: transformações recentes e debates atuais. São Paulo: Xamã; Goiânia: Alternativa, 2003, p. 17-30.

DOURADO, Luiz Fernandes. Políticas e gestão da educação superior no Brasil: múltiplas regulações. In: DOURADO, Luiz Fernandes (org.). Políticas e gestão da educação no Brasil: novos marcos regulatórios. São Paulo: Xamã, 2009, p. 149-167.

DRUCKER, Peter. Pessoas e desempenhos. Rio de Janeiro: Elsevier, 2012.

EYNG, Ana Maria. Políticas e gestação superior: desafios e perspectivas. ljuí: Unijuí, 2007.

FERREIRA, Suely. Reformas na educação superior: novas regulações e a reconfiguração da universidade. Educação Unisinos, São Leopoldo, 2015, p. 122-131.

FRIGOTTO, Gaudêncio. $O$ enfoque da dialética materialista histórica na pesquisa educacional. In: Fazenda, Ivani (org.). Metodologia da pesquisa educacional. São Paulo: Cortez, 1991, p. 69 - 91.

GARCIA, Mauricio. Gestão profissional em instituições privadas de ensino superior: um guia de sobrevivência para mantenedores, acionistas, reitores, pró-reitores, diretores, coordenadores, gerentes e outros gestores institucionais. Brasil: Hoper, 2006.

GOMES, Alfredo Machado. Política de avaliação da educação superior: controle e massificação. Revista Educ. Soc., Campinas, v. 23, n. 80, 2002, p. 277-300.

HINO, Satoshi. O pensamento toyota: princípios de gestão para um crescimento duradouro. Porto Alegre: Bookman, 2009.

JANELA, Afonso. A. Avaliação educacional: regulação e emancipação. São Paulo: Cortez, 2010.

LAVILLE, Christian. DIONNE, Jean. A construção do saber: manual de metodologia da pesquisa em ciências humanas. Porto Alegre: Artmed; Belo Horizonte: UFMG, 2009.

LEITE, Denise. Avaliação participativa e qualidade: os atores locais em foco. Porto Alegre: Sulina, 2009.

LIKER, Jeffrey. O modelo toyota: 14 princípios de gestão do maior fabricante do mundo. Porto Alegre: Bookman, 2007.

LICÍNIO LIMA. A escola como organização educativa. São Paulo: Cortez, 2011.

MELLO, Guiomar Namo. Escolas eficazes: um tema revisitado. Brasília: Ipea, 1993.

MENEGOLLA Maximiliano; SANT'ANNA, Ilza Martins. Por que planejar? Como planejar? Petrópolis: Vozes, 2003. 
MOROSINI, Marilia. (Org). A universidade no Brasil: concepções e modelos. Brasília: Inep, 2006.

NEVES, Lucia Maria Wanderley. Políticas sociais contemporâneas: teses para discussão. In: Políticas públicas \& Serviço social: análises e debates. Rio de Janeiro: Observatório Social, 2008.

PADILHA, Paulo Roberto. Planejamento dialógico: como construir o projeto político pedagógico da escola. São Paulo: Cortez; Instituto Paulo Freire, 2003.

RISTOFF, Dilvo. Construindo outra educação: tendências e desafios da educação brasileira. Florianópolis: Insular, 2011.

RISTOFF, Dilvo. Universidade em foco: reflexões sobre a educação superior. Florianópolis: Insular, 1999.

ROCHA, Everardo. Representações do consumo. Rio de Janeiro: Mauad/PUC-RIO, 2012.

SGUISSARDI, Valdemar. Reforma universitária no Brasil 1995-2006: precária trajetória e incerto futuro. Revista Educ. Soc., Campinas, v. 27, n. 96, 2006, p. 1021-1056.

TOFFIK, Sawaia Clovis. A gestão acadêmica nas instituições de ensino superior. In: COLOMBO, Sonia Simões (org.). Gestão universitária os caminhos para a excelência. Porto Alegre: Penso, 2013, p. 104-107.

TORRES, Alexandre Pavan. Administração estratégica: conceitos, roteiro prático, casos. Rio de Janeiro: Reichnann e Affonso, 2004.

VIEIRA, Sofia Lerche. Escola: função social, gestão e politica educacional. In: FERREIRA, Naura Syria. Carapeto (org.). Gestão da educação: impasses, perspectivas e compromissos. São Paulo: Cortez, 2000, p. 129-145.

Felipe Barbosa Ferronato é advogado e mestre em Educação pela Univas.

Endereço: Americo Totti, 286/6 - 3713-000 - Alfenas - MG - Brasil.

E-mail: felipeferronato@uol.com.br.

Recebido em 6 de junho de 2016.

Aceito em 24 de outubro de 2016. 